\title{
"I Am Getting Healthier". Perceptions of Urban Aboriginal and Torres Strait Islander People in a Chronic Disease Self-Management and Rehabilitation Program
}

\author{
Alison Nelson', Kyly Mills², Samara Dargan', Chantel Roder ${ }^{1}$ \\ ${ }^{1}$ The Institute for Urban Indigenous Health, Bowen Hills, Australia \\ ${ }^{2}$ Queensland University of Technology, Brisbane, Australia \\ Email: alison.nelson@iuih.org.au
}

Received 22 March 2016; accepted 12 April 2016; published 15 April 2016

Copyright (C) 2016 by authors and Scientific Research Publishing Inc.

This work is licensed under the Creative Commons Attribution International License (CC BY). http://creativecommons.org/licenses/by/4.0/

(c) (i) Open Access

\section{Abstract}

Chronic disease is a main contributor to the disproportionately high burden of illness experienced by Aboriginal and Torres Strait Islander Australians. However, there are very few programs addressing chronic disease self-management and rehabilitation which are designed specifically for urban Aboriginal and Torres Strait Islander people. This paper aims to explore client and staff perceptions of the Work It out Program, a chronic disease rehabilitation and self-management program designed for urban Aboriginal and Torres Strait Islander people. The study used a mixed methods approach to explore the success, barriers and self-reported outcomes of the program. Quantitative data were collected through a structured survey, comprising social and demographic data. Qualitative data were collected through interviews using Most Significant Change theory. Twenty-eight participants were recruited, 6 staff and 22 clients $(M=7, F=21)$ with an age range between 21 and 79 years of age (Mean $=59.00, S D=17.63$ ). Interviews were completed in 2013 across four Work It out locations in Southeast Queensland. Semi-structured interviews were conducted either individually or in groups of two or three, depending on the participants' preference. Thematic analysis of the data revealed six main themes; physical changes, lifestyle improvements, social and emotional well-being, perceptions about the successful features of the program, perceived barriers to the program and changes for the future. This exploratory study found that clients and staff involved in the Work It out Program perceived it as an effective self-management and rehabilitation program for urban Aboriginal and Torres Strait Islander Australians. Further evaluation with a larger sample size is warranted in order to establish further outcomes of the program. 


\section{Keywords}

\section{Indigenous Health, Chronic Disease, Self-Management, Rehabilitation}

\section{Introduction}

Chronic disease is a main contributor to the disproportionately high burden of illness experienced by Aboriginal and Torres Strait Islander Australians [1]-[3]. National data indicate that 50\% of Aboriginal and Torres Strait Islander people are living with a chronic condition or disability, and chronic diseases contribute to five times the hospitalisation rate for indigenous people living in Queensland, than for the non-indigenous population [2] [4]. The ability of mainstream aged care services to meet the complex needs of indigenous Australians who are ageing younger, many of whom have experienced chronic health conditions throughout their lives, such as diabetes and cardiovascular diseases has also been questioned [5]. Considering the view of indigenous health as "...not just the physical wellbeing of an individual but also the social, emotional and cultural well-being of the whole community..." [6], the negative impacts of chronic disease are likely to extend from affected individuals to their families and communities. Effective management of these conditions is critical in closing the life expectancy gap between indigenous and non-indigenous Australians within a generation.

Several features have been identified as critical in development of culturally safe chronic disease management and rehabilitation programs for Aboriginal and Torres Strait Islander people and for culturally and linguistically diverse populations more generally [7] [8]. These include information that is accessible and culturally relevant, adequate aboriginal community engagement, utilising local knowledge, strong leadership, shared responsibilities, sustainable resources and integrated data and systems, and the involvement of Aboriginal and Torres Strait Islander staff in service delivery and the integration of care across conditions and sectors [7]-[9]. Brach \& Fraser [10], also suggest that culturally safe and competent services will translate into better health via the impact they have on improved communication, increased trust in the health system, greater knowledge about health and services in the local community and expanded cultural understanding within the health system.

Several initiatives have been developed to address chronic condition self-management for all Australians and these have been adapted at times for Aboriginal and Torres Strait Islander Australians [11]. The Flinders Program $^{\mathrm{TM}}$ [12] offers a researched set of specific principles of self-management, now widely adopted in clinical settings throughout Australia. The Flinders Program promotes structural reorientation of services at a clinical level to produce an organisation that is conducive to self-management. The program has five key functions: generic and holistic chronic condition management, case-management, self-management support, systematic and organisational change and clinician change [12]. Additionally, it correlates a "good" self-manager with a set of pertinent qualities: having knowledge of their condition; following a treatment plan of which they actively share in decisions with health professionals; monitoring and managing signs, symptoms and impacts of their condition on their physical, emotional and social life; adopting lifestyles to promote health; and having confidence and access to use support services [12]. Evaluation of the Flinders Program ${ }^{\mathrm{TM}}$ used in rural and remote Aboriginal communities in South Australia showed promising results, with 36 clients demonstrating statistically significant and small but clinically important improvements in body massindex, total cholesterol, triglyceride and LDL and HbA1c measurements [11].

Whilst there have been a small number of chronic disease self-management programs targeting Aboriginal and Torres Strait Islander people, these have generally focused on one-on-one goal setting and monitoring techniques, structured care-planning and care coordination, health promotion, self-management support and other care management strategies provided at the clinical level [11] [13]-[17]. Chronic disease programs that are delivered in group settings are rare and have centred on providing community (peer) support, and/or physical activity and nutrition interventions rather than chronic disease management or rehabilitation [11] [18]-[20]. Additionally, the majority of these programs are implemented in rural/remote settings. Whilst mainstream chronic disease rehabilitation programs exist, they are usually specific to one particular condition and often are not accessed by Aboriginal and Torres Strait Islander people [21]. Greater uptake and outcomes have been reported when programs are delivered within an Aboriginal and Torres Strait islander community-controlled health service with opportunity for "yarning" (talking informally) and tailored exercise [22]. Significantly, there appears 
to be a shortcoming in the development of high quality group programs focusing on holistic chronic disease self-management and rehabilitation for Aboriginal and Torres Strait Islander people, coordinated by a team of qualified professionals in an urban environment. There is also an indicated need for methodologically sound evaluative designs for interventions in indigenous-specific settings [23].

The Work It out Program was developed as a chronic disease self-management and rehabilitation program for urban Aboriginal and Torres Strait Islander Australians in South East Queensland by The Institute for Urban Indigenous Health. The program adopts a holistic and inter-professional allied health approach to chronic disease management in a group setting. Work It out aims to improve or stabilise key health outcome indicators in terms of individual chronic disease/s; reduce activity limitation; improve clients' knowledge and confidence in the independent management of their chronic disease, increase understanding on how to live a healthy life with chronic disease; and foster behaviour change in adopting a healthy lifestyle.

The Work It out Program commenced in August 2011 and now runs across thirteen locations, with over 800 participants to date. The program runs 2 - 4 times a week in each location and comprises a 45 minute education session delivered by different allied health professionals, followed by a one hour tailored exercise program and a healthy snack. There are 24 education sessions in total, including sessions on energy conservation (occupational therapy) stress management (psychology), staying strong (exercise physiology) and healthy eating (dietician). There are no strict entry and exit points in the program. This flexibility in design is a key feature of successful approaches to health care provision with Aboriginal and Torres Strait Islander people [24]. Independent of the group sessions, clients have the opportunity to meet one-on-one with allied health professionals for assistance with self-management strategies or rehabilitation needs specific to their chronic condition/s. Work It out is delivered by Aboriginal and Torres Strait Islander and non-indigenous health professionals, working together within and Aboriginal and Torres Strait Islander community-controlled framework.

This paper aims to explore client and staff perceptions of the Work It out Program. This includes features which contribute to the program's success, barriers to the program and self-reported outcomes from clients in the program.

\section{Methods}

This research was informed by a constructivist epistemology, acknowledging that knowledge is situated and socially constructed [25]. A mixed methodology design was used for this study as this approach is deemed most appropriate and valuable when the focus of the research is multi-faceted and complex [26]. The qualitative methodology comprised a semi-structured interview of 11 questions which were developed using "Most Significant Change (MSC) Theory [27]. The MSC technique is a relatively new dialogue method for monitoring and evaluating complex interventions [27]. Questions were developed to determine the most significant changes the regular Work It out clients have seen within themselves, or that staff had seen in clients, and other personal lifestyle improvements the program had facilitated with clients. This information was then discussed with the client and staff participants at regular intervals in order to gain further input on their collective impressions of the most significant changes occurring as a result of the program. The quantitative methodology comprised collection of demographic information from clients via surveys and clinical assessment.

\subsection{Ethics}

This study was approved by the University of Queensland Behavioural and Social Sciences Ethical review Committee and by the board of The Institute for Urban Indigenous Health. All study participants provided informed written consent prior to their participation. In addition, the research agenda is embedded into the WIO program. An education session titled "The Big Picture" is performed by the research assistants of the program, once each 12 week cycle. This is an interactive session where participants are encouraged to "yarn up" about the meaning of research, the data and outcomes, and creative ways in presenting these outcomes to appropriate agencies and across communities. This session ensures absolute transparency and openness surrounding the ongoing research. It also provides a platform for ownership of the program which aids sustainability [28].

\subsection{Participants}

All regular participants of the Work It out Program were invited to take part in this study. Of those approached, 
28 interviews were conducted over an eight month period across 4 Work It out locations. Interviews were conducted with six staff, 22 clients (including 7 males, 21 females) with the age of interviewees ranging from 21 to 77 years old. Of the six staff interviewed, all were female health professionals. Three staff participants were Aboriginal and the other three were non-indigenous. The age range of staff participants was 21 to 48 years. All interviewees had been involved with the Work It out Program for at least 6 months.

\subsection{Data Collection}

Demographic information (age, sex, medical conditions) was collected from client participants when they entered the program using a pen and paper survey. Participants self-completed the survey (with literacy support available). Survey completion was voluntary and responses confidential. More in-depth social and demographic characteristics were collected from the clients' Adult Health Check, undertaken at participating ATSICCHSs as mandatory for entry into the program. Quantitative measures were also routinely collected with short-term changes in anthropometry measures for participants with cardiovascular disease reported elsewhere (Mills et al., submitted for publication). Individual or small group interviews (depending on client's preference) were conducted with a cross-section of participants from different locations, ages and genders. Interviews were semistructured and sought participant feedback regarding their overall perceptions of the program, reasons for entering the program and the most significant changes they had seen as a result of the program. This approach also allowed for clients and associated staff to provide process evaluation type feedback, detailing what they believe is working for the program, what barriers they believe exist for other potential clients and what changes they would like to see in the program. Each interview took between 5 minutes to 50 minutes to complete.

Interviews took place usually before or after the Work It out Program in a quiet location convenient to participants. Interviews were transcribed verbatim, de-identified and stored in password protected computer files or locked filing cabinets.

\subsection{Data Analysis}

Quantitative social and demographic descriptive data were summarised using counts and percentages for categorical data, and means and standard deviations for continuous data. Once interviews were completed, qualitative data were analysed thematically. A representative sample of transcripts was read independently by three members of the research team who then met to develop a thematic coding tree using a process of consensus. Once the themes were identified, one researcher proceeded to code the remaining data. These themes were then presented to client and staff participants for further feedback until consensus was reached that these were the most significant.

\section{Results}

\subsection{Social and Demographic Profile}

Of the clients interviewed, complete sets of social and demographic quantitative data were available for 16 participants. Almost all clients identified as Aboriginal $(\mathrm{n}=15,93.75 \%)$ with one $(6.25 \%)$ identifying as Torres Strait Islander. To ensure diverse accounts of the program across the lifespan were captured, the age range of participants was considerable, spanning from 21 to 79 years (mean $=59.90$ years, SD $=17.63$ ). All interviewees had at least one chronic condition (mean $=3.88, \mathrm{SD}=1.50$ ), with most having several comorbidities and one participant suffering up to seven chronic conditions. The most common conditions experienced by the interviewees were social and emotional wellbeing conditions (i.e. depression/anxiety) ( $\mathrm{n}=10,62.5 \%$ ), musculoskeletal conditions $(n=7,43.75 \%)$, diabetes $(n=6,37.50 \%)$ and respiratory conditions $(n=6,37.50 \%)$. All participants had at least one risk factor for chronic disease (mean $=2.44, \mathrm{SD}=1.09$ ), the most frequent of which was hypertension $(n=15,93.75 \%)$ and overweight/obesity $(n=15,93.75 \%)$. Most participants were married $(n=$ 8, 66.66\%) and not currently employed $(\mathrm{n}=14,93.33 \%)$, with three participants $(23.07 \%)$ acting as a carer for someone (other than their own children) and four (30.76\%) requiring the need for a carer themselves.

Six main themes were identified from the qualitative analysis; physical changes, lifestyle improvements, social and emotional well-being, perceptions about the features of the program that worked and perceived barriers to the program and changes for the future. Each theme will be reported with participant's quotes used as illustration. 


\subsection{Physical Changes}

Participants identified a wide range of physical changes as a result of the Work It out Program, including improved balance and strength. Most commonly, physical changes identified were increased energy levels and fitness.

"I didn't know that just sitting in a chair all day was making my body weaker and weaker. And when I got here, I could hardly walk on the treadmill for 5 minutes, I was so puffed... Now I do around 40 minutes at a good pace, and I am still not puffing at the end. Big improvement from 5 minutes! (Aunty Molly).

You really feel invigorated when you go here... from a morning session at the gym, and you go home, and you look for things to do (Aunty Anne).

Weight loss or changes in waist circumference were other noted areas of physical change by both health professionals and participants. For example, one dietician noted of her client that ...her actual measurements have changed, like centimetres off her hips and waist have been really good" (Jane, Dietician).

Participants also reported physical changes in terms of management of their chronic diseases. This included better controlled blood glucose levels in diabetes and improved blood pressure. For instance, Sally reported,

"I had my HBA1C done the other day and it was 5.7, and my endocrinologist was so happy, she couldn't believe it, because it was 7.9 the last one that I had taken. I have been able to drop back my insulin, because of the weight loss and because of the activity" (Sally).

Participants also noted improvements in conditions causing chronic pain, blood pressure and respiratory conditions.

"I am getting healthier, I am getting fit. I am more active than I used to be. You know I have scoliosis in my back, and I am finding that I am not getting as much pain."(Aunty Joanie).

"I can't tell you how much my asthma has disappeared... I haven't used my spray for months and my blood pressure has been so good, when I was first coming I couldn't do the exercise, cause my blood pressure was too high... and now my blood pressure has been just so good every time" (Aunty Lorraine).

For Sally, the link between the program, her diabetes management, injury rehabilitation and increased fitness was clear.

"I have lost 10 kilos since Xmas, and my blood sugar is better controlled... I was too sore to get anywhere, and now even cleaning my house and that stuff, I just do stuff I never thought I could do before because of my back." (Sally).

Participants in the Work It out Program also identified that it has resulted in less visits to the doctor because their chronic disease was being better managed. For instance, Aunty Lorraine reported,

“...it means you're not getting sick so much and you're not going to see the Doctor so much, and you don't end up in hospital. I think it must be saving a great many hospital beds".

\subsection{Social and Emotional Changes}

Overwhelmingly, participants reported improvements in emotional well-being and increased social connectedness as a part of the Work It out Program. Participants noted they felt more confident and were enjoying life more due to their involvement in the program.

Confidence I think. Knowing that I can control what happens to my body, and I can take care of myself, and that I can do things that I thought that I couldn't do... and get my health back on track (Sally).

You really look forward to life, and you feel like jumping into life... cause there is this great big wonderful world out there now, and it must be because I am feeling much better yourself, probably physically, emotionally too, yeah mentally and in every way. It's just like opening a door (Aunty Anne).

There were also reports of a decrease in feelings of depression or anxiety. This was often expressed as being able to cope with challenges in life a bit better. For instance, Aunty Molly reported, "Through this program, I have this extra strength. Now I don't do all that worry”. Other clients expressed greater feelings of happiness and feeling less angry or "cranky" as a result of the Work It out Program.

But the most important thing is that I am much happier when I come here on the day, and when I don't come, I feel very sluggish, at home and I feel down and just not happy, but after coming here and doing the program, you feel good, you feel happy, you want to do more things (Aunty Sharon).

[The program has] made me a better man to live with... I am not as crabby as I used to be. I would say that if this program wasn't around I would be so angry I'd be back on the grog (Uncle Allan). 
Social connectedness was also a strong theme in the results collated. Participants reported the benefits of having a place to meet others, to get "out of the house" and this was consistent across different ages. Social connections were both with old friends as well as making new friends or re-connecting with family after several years. For instance, Aunty Odette noted, "the best thing I think is meeting all these friends, all the people, I have absolutely loved it". Aunty Julie reported "I feel the company as well. If I weren't here, I'd be at home lying on the couch eating bread and butter... watching TV. Aunty Molly had reconnected with family through the program and was really pleased..." We've found out that other woman is my cousin. We didn't know that before. Another participant found a lost sister" (Aunty Molly).

Participants also noted that the approach of the staff in the program, and the program's development itself was a source of their emotional well-being as they felt valued that a program was provided to meet their needs.

I felt pleased that I was referred... I honestly thought people wouldn't bother about older people... the girls (staff) seem to be caring, they seem genuine. They want to help you. They seem to be really interested in you. And when I was young, if you were Aboriginal, people often didn't want to sit next to you. They steered away from you (Aunty Anne).

The program is the greatest thing that could happen for Aboriginal health. People are not shamed or frightened to come here. Because we got each other (Aunty Julie).

This sense of connection also led to a reported feeling of responsibility to help each other and to ensure the success of the program. For instance, Aunty Lorraine reported, "It fosters... relationships so that people keep coming back... Because like I said, I didn't want to come today (laughs) but you do come”.

\subsection{Lifestyle Improvements}

Participants reported a range of ways in which their lifestyles had improved. These included improved eating habits (e.g. less sugar, less bread), a more active lifestyle, reduced gambling and reduced tobacco and alcohol consumption (I gave up drinking-Uncle Alan). For instance Aunty Molly reported,

I don't eat so much anymore. I used to sit down and eat and eat and eat. Now I think, if I eat too much, I will muck up all that exercise and I will have been coming here for nothing (Aunty Molly).

The impact of these changes also influenced the families of Work It out participants as they would encourage changes more broadly.

...before I would never have thought about buying a bike and riding down the road, which I do now. I ride to the gym, I ride to the markets on a Sunday morning, I have also got my wife into riding a bike aswell, so we might ride down to Burleigh have a coffee and ride home again (Uncle Laurie).

Like Uncle Laurie, (above), many participants also reported that they had taken up new activities as a result of the improvements in their overall health. They also reported greater mobility around home and an improved ability to attend to activities of daily living.

For instance Aunty Lorraine reported "getting out of a chair and standing up, all that becomes easier with the exercise program", and Aunty Odette noted,

"Well I have been able to walk up steps-that is the main thing, I couldn't do that before. I am not kidding, I just couldn't. And my balance was off, and I did all this walking balance thing which was good. It works, it really works. ...But now wherever I go and there are a few steps anywhere, it doesn't worry me. I can walk up those few steps, like when I go shopping, and you are going somewhere" (Aunty Odette).

Financial benefits of the program were also identified by participants. These included spending less on medicines due to less need to take them and increasing income through the ability to return to paid employment. Sally noted that the program had saved her money "because I have been able to drop the level of insulin [under her Doctor's direction], and stop buying medicine”.

Lifestyle changes were more broadly reported by several participants who noted that the Work It out Program had provided a much-needed purpose and structure in their daily or weekly routines and they had begun to set goals as part of their involvement in the program. For instance, Aunty Julie reported,

When my husband was put in the nursing home, I got so depressed... all that I wanted to do was go to the pokies... and that is what I was doing all the time. I have wasted so much money. And now I have something positive to do, by coming here (Aunty Julie).

Sally also reported improvements in her family relationships and an increase in purpose in her everyday life as a result of Work It out.

Well apart from going for a walk each night with my husband, I have set myself a goal, because we did some 
goal work through WIO, and one of mine was to do something active every day, as well as my walking, and to do something every weekend with my stepdaughter. And that is something that has really changed is my relationship with my stepdaughter. She said to me last weekend, "I love how you are taking me to the park now, and I love how you are spending time with me”. (Sally).

\subsection{Key Features of the Work It out Program}

Participants identified several key features of the Work It out Program which they felt made it successful. These included the approach of the staff ("skilled, accepting, friendly, culturally aware”), and the program (“empowering, flexible”), the delivery of education sessions and the provision of a comfortable meeting place. Aunty Molly noted that

"I have been to other exercise places before where they are all white, and wear leotards, and no one talks to you... I felt so uncomfortable... whereas we can come here, not worrying how we are looking, and we still feel good".

Sally also identified the "atmosphere of it, with everyone willing to share, and everybody willing to listen to everybody else, there is no judgement". Aunty Lorraine also reported, "I think it works so well because of the staff we have are great. I think we have very attentive staff and very thoughtful staff... the care and attention it is given to each of us individually".

Participants also appreciated the ability to access Allied health staff, both within the program and in individual appointments. They noted that this often reduced their reliance on needing to see their general practitioner. For example, Aunty Anne reported,

I don't have to run to a doctor, I can just sit down with the Exercise Physiologist and say "what muscle is that?" if they give you a new exercise, and they will tell you and you go home feeling confident in whatever they do (Aunty Anne).

The importance of addressing logistical aspects of the program was also highlighted by participants, including provision of transport, cost and the inclusion of a link with the clinic, in the form of the Aboriginal and Torres Strait Islander health worker. Aunty Anne noted "we get picked up, and dropped off and it is not costing us anything. And we are benefitting so much from it”.

\subsection{Barriers to the Program}

Participants identified several potential barriers to coming to the Work It out Program. These included not knowing enough about the program, not having enough programs in enough locations, lacking confidence to try something new, lacking motivation, confidence or initiative to undertake self-management and people's general attitude to health and exercise. For instance, Aunty Anne noted that "I thought I was too old to do it... and I thought I was too big that I would never be successful at achieving anything”. Lester also identified that

"People are shy too. I mean to get there amongst a new group of people it always takes a bit of a push. A lot of other people would need a push to start but they would continue once they started.

Suggestions to remedy some of these barriers included having ambassadors for the program who were regular members, giving information to referring GP's to pass on to clients at the point of referral, having advertising materials in the clinics and having a "come and try" session where clients could gain a taste of the program.

\subsection{Changes}

Participants also identified some changes they would like to see in the Work It out Program in the future. These included increasing the number of days and times available to attend the program and having staff prescribe more activities which could be done at home in between the program. For instance Sally suggested "If we had activities to do at home and things like that, I think that would be a big benefit”. Staff participants also identified that there was a need to help clients plan for life after they left the program and an ongoing need for communication processes which linked the program back to the primary health care service.

\section{Discussion}

Results from the qualitative interviews suggest that participants of the Work It out Program perceive it as highly beneficial in supporting them to improve their physical health and social and emotional well-being. The fact that 
physical changes were repeatedly reported by clients is an important finding. Even modest loss in waist circumference and weight were associated with significant reductions in systolic and diastolic BP in remote far North-Queensland Aboriginal and Torres Strait Islander communities [29]. The physical changes in weight and waist circumference in work it out clients, even marginally, could have significant health benefits for this population.

As the most common chronic condition experienced by clients in this sample were social and emotional wellbeing conditions, perceived improvements in this area are a significant outcome from program attendance. This positive change is important, as it not only appears to result in an improved mood and a reduction in symptoms of depression and anxiety, but also has the potential to increase participation in social, community and cultural activities for this cohort. The social connectedness reported by clients is of particular importance for Aboriginal and Torres Strait Islander people who may have been displaced by previous government policies [30]. This social connectedness or "re-connectedness" is a strength of Aboriginal and Torres Strait Islander communities which the Work It out Program was able to foster in an urban context, where people can be more disparately placed and less connected [31].

Client responses reflected the features of a "good" self-manager in that they expressed increased knowledge of their conditions, they monitored and managed their symptoms and they expressed they ways in which the program impacted on their conditions [12]. Participants also identified lifestyle changes they had made as a result of the Work It out Program and expressed increased confidence and vitality in living their lives with a chronic condition [12]. This increased confidence may help mitigate one of the identified barriers of attending the program, in that once participants had joined the program, their confidence increased. Other barriers identified could be addressed through a marketing campaign to promote the program amongst community members and increasing the number of locations in which the program is available.

Participants' responses also reflected features of a culturally safe program in that there was engagement with Aboriginal and Torres Strait Islander people, information was provided in an appropriate and digestible way, there was integration with the health service and responsibilities were shared across clients and staff and between clients as well [8].

Although not quantified in this study, participant comments regarding decreased rates of hospitalisation bear further consideration. The features of the Work It out Program reported by participants, such as the social connections and the ability to manage chronic condition symptoms are consistent with the priorities identified as key targets for preventable hospital admissions [32]. Self-management skills and personal resilience were also identified as predictors of hospitalisations and these were also reflected in participant comments. This suggests that the Work It out Program has some evidence for making claims of preventing hospitalisations and this could be further investigated and quantified.

There were several limitations of this study. This included that the participants were already engaged in the program which may have influenced their comments favourably for the program. In addition, the sample size was quite small which makes generalisation of the results difficult. It is recommended that this evaluation is followed up with a quantitative evaluation of a larger sample size.

\section{Conclusion}

This exploratory study found that clients and staff involved in the Work It out Program perceived it as an effective self-management and rehabilitation program for urban Aboriginal and Torres Strait Islander Australians. Participants feel that the program design (based on a culturally safe and responsive approach) has strengthened the physical and social and emotional well-being of clients. Further quantitative analysis of program outcomes is warranted to further evaluate the outcomes of the program, although this also needs to take place in a culturally responsive manner.

\section{Acknowledgements}

This research was funded in part through the Commonwealth Department of Health and Ageing.

\section{References}

[1] Australian Burea of Statistics (ABS) (2006) National Aboriginal and Torres Strait Islander Health Survey 2004-2005, 
cat. no. 4715.0. ABS, Canberra.

[2] Australian Bureau of Statistics (ABS) (2013) Australian Aboriginal and Torres Strait Islander Health Survey, cat. no. 4727.0.55.001. ABS, Canberra.

[3] Australian Institute of Health and Welfare (AIHW) (2012) Risk Factors Contributing to Chronic Disease, cat. no. PHE 157. AIHW, Canberra.

[4] Australian Institute of Health and Welfare (AIHW) (2010) Contribution of Chronic Disease to the Gap in Adult Mortality between Aboriginal and Torres Strait Islander and Other Australians, cat. no. IHW 48. AIHW, Canberra.

[5] Waugh, E. and Mackenzie, L. (2011) Ageing Well from an Urban Indigenous Australian Perspective. Australian Occupational Therapy Journal, 58, 25-33. http://dx.doi.org/10.1111/j.1440-1630.2010.00914.x

[6] National Aboriginal Health Strategy Working Party (NAHSWP) (1989) A National Aboriginal Health Strategy—Report. Australian Government Publishing Service, Canberra. http://www.health.gov.au/internet/main/publishing.nsf/Content/health-oatsih-pubs-NAHS1998

[7] Henderson, S. (2011) The Effectiveness of Culturally Appropriate Interventions to Manage or Prevent Chronic Disease in Culturally and Linguistically Diverse Communities: A Systematic Literature Review. Health and Social Care in the Community, 19, 225-249. http://dx.doi.org/10.1111/j.1365-2524.2010.00972.x

[8] Liaw, S.T., Lau, P., Pyett, P., Furler, J., Burchell, M., Rowley, K. and Kelaher, M. (2011) Successful Chronic Disease Care for Aboriginal Australians Requires Cultural Competence. Australian and New Zealand Journal of Public Health, 35, 238-248. http://dx.doi.org/10.1111/j.1753-6405.2011.00701.x

[9] Frølich, A., Høst, D., Schnor, H., Nørgaard, A., Ravn-Jensen, C., Borg, E. and Hendriksen, C. (2010) Integration of Healthcare Rehabilitation in Chronic Conditions. International Journal of Integrated Care, 10, e033. http://dx.doi.org/10.5334/ijic.507

[10] Brach, C. and Fraser, I. (2000) Can Cultural Competency Reduce Racial and Ethnic Disparities? A Review and Conceptual Model. Medical Care Research and Review, 57, 181-217. http://dx.doi.org/10.1177/107755800773743655

[11] Kowanko, I., Helps, Y., Harvey, P., Battersby, M., McCurry, B., Carbine, R., Boyd, J. and Abdulla, O. (2012) Chronic Condition Management Strategies in Aborginal Communities: Final Report 2011. Flinders University and the Aboriginal Health Council of South Australia, Adelaide.

[12] Flinders Human Behaviour and Health Research Unit F. U. (2010) The Flinders Program for Chronic Condition Management: Information Paper. Flinders University, Adelaide. http://www.flinders.edu.au/medicine/fms/sites/FHBHRU/documents/publications/FLINDERS\%20PROGRAM\%20IN FORMATION\%20PAPER\%20FINAL_M.pdf

[13] Ah Kit, J., Prideaux, C., Harvey, P., Collins, J., Battersby, M., Mills, D. and Dansie, S. (2003) Chronic Disease SelfManagement in Aboriginal Communities: Towards a Sustainable Program of Care in Rural Communities. [Special Issue: The Management of Chronic Disease in Primary Care Settings]. Australian Journal of Primary Health, 9, 168-176. http://dx.doi.org/10.1071/PY03043

[14] Pearce, S., Thomas, A.-M. and Gorman, D. (2005) The Better Living Diabetes Project. Aboriginal and Islander Health Worker Journal, 29, 4-6.

[15] Abbott, P., Davison, J. and Moore, L. (2007) Challenges and Benefits of Implementing a Chronic Disease Self-Management Program in an Aboriginal Community Controlled Health Setting. Australian Journal of Primary Health, 13, 35-39. http://dx.doi.org/10.1071/PY07036

[16] D’Abbs, P., Schmidt, B., Dougherty, K. and Senior, K. (2008) Implementing a Chronic Disease Strategy in Two Remote Indigenous Australian Settings: A Multi-Method Pilot Evaluation. Australian Journal of Rural Health, 16, 67-74. http://dx.doi.org/10.1111/j.1440-1584.2008.00955.x

[17] Harvey, P.W., Petkov, J., Kowanko, I., Helps, Y. and Battersby, M. (2013) Chronic Condition Management and Self-Management in Aboriginal Communities in South Australia: Outcomes of a Longitudinal Study. Australian Health Review, 32, 330-338. http://dx.doi.org/10.1071/AH080330

[18] Chan, L.C., Ware, R., Kesting, J., Marczak, M., Good, D. and Shaw, J.T. (2007) Short Term Efficacy of a Lifestyle Intervention Programme on Cardiovascular Health Outcome in Overweight Indigenous Australians with and without Type 2 Diabetes Mellitus: The Healthy Lifestyle Programme (HELP). Diabetes Research and Clinical Practice, 75, 65-71. http://dx.doi.org/10.1016/j.diabres.2006.04.012

[19] Rowley, K.G., Daniel, M., Skinner, K., Skinner, M., White, G.A. and O’Dea, K. (2000) Effectiveness of a Community-Directed "Healthy Lifestyle" Program in a Remote Australian Aboriginal Community. Australian and New Zealand Journal of Public Health, 24, 136-144. http://dx.doi.org/10.1111/j.1467-842X.2000.tb00133.x

[20] Canuto, K., McDermott, R., Cargo, M. and Esterman, A. (2011) Study Protocol: A Pragmatic Randomised Controlled Trial of a 12-Week Physical Activity and Nutritional Education Program for Overweight Aboriginal and Torres Strait Islander Women. BMC Public Health, 11, 655. http://dx.doi.org/10.1186/1471-2458-11-655 
[21] Clark, R., Coffee, N., Turner, D. , Eckert, K., van Gaans, D., Wilkinson, D., Stewart, S. and Tonkin, A. (2014) Access to Cardiac Rehabilitation Does Not Equate to Attendance. European Journal of Cardiovascular Nursing, 13, $235-242$. http://dx.doi.org/10.1177/1474515113486376

[22] Dimer, L., Dowling, T., Jones, J., Cheetham, C., Thomas, T., Smith, J., McManus, A. and Maiorana, A. (2013) Build It and They Will Come: Outcomes from a Successful Cardiac Rehabilitation Program at an Aboriginal Medical Service. Australian Health Review, 37, 79-82. http://dx.doi.org/10.1071/AH11122

[23] Clifford, A., Pulver, L.J., Richmond, R., Shakeshaft, A. and Ivers, R. (2011) Smoking, Nutrition, Alcohol and Physical Activity Interventions Targeting Indigenous Australians: Rigorous Evaluations and New Directions Needed. Australian and New Zealand Journal of Public Health, 35, 38-46. http://dx.doi.org/10.1111/j.1753-6405.2010.00631.x

[24] Nelson, A. and Allison, H. (2007) Relationships: The Key to Effective Occupational Therapy Practice with Urban Australian Indigenous Children. Occupational Therapy International, 14, 57-70. http://dx.doi.org/10.1002/oti.224

[25] Guba, E. and Lincoln, Y. (1994) Competing Paradigms in Qualitative Research. In: Denzin, N. and Lincoln, Y., Eds., Handbook of Qualitative Research, Sage, Thousand Oaks, 105-117.

[26] Tariq, S. and Woodman, J. (2013) Using Mixed Methods in Health Research. Journal of the Royal Society of Medicine Short Reports, 4, 2042533313479197. http://dx.doi.org/10.1177/2042533313479197

[27] Davies, R. and Dart, J. (2005) The “Most Significant Change” (MSC) Technique. A Guide to Its Use. http://www.mande.co.uk/docs/MSCGuide.pdf

[28] NHMRC (2010) The NHMRC Road Map II: A Strategic Framework for Improving the Health of Aboriginal and Torres Strait Islander People through Research. NHMRC, Canberra.

[29] D’Onise, K., McDermott, R.A. and Campbell, S.K. (2013) Benefits of Modest Weight or Waist Circumference Loss in a Remote North Queensland Indigenous Population. Australian and New Zealand Journal of Public Health, 37, 345349. http://dx.doi.org/10.1111/1753-6405.12082

[30] Carson, B., Dunbar, T., Chenhall, R.D. and Bailie, R. (Eds.) (2007) Social Determinants of Indigenous Health. Allen and Unwin, Crows Nest.

[31] Brough, M., Bond, C., Hunt, J., Jenkins, D., Shannon, C. and Schubert, L. (2006) Social Capital Meets Identity: Aboriginality in an Urban Setting. Journal of Sociology, 42, 396-411. http://dx.doi.org/10.1177/1440783306069996

[32] Muenchberger, H. and Kendall, E. (2010) Predictors of Preventable Hospitalization in Chronic Disease: Priorities for Change. Journal of Public Health Policy, 31, 150-163. http://dx.doi.org/10.1057/jphp.2010.3 